\title{
The spillover effect of technological progress based on two sector model: An empirical study of Chinese manufacturing sector ${ }^{\diamond}$
}

\author{
Sun Xiao-hua a, Wang Yun ${ }^{*}$ \\ a b Dalian University of Technology, Department of Economics, Dalian, China. \\ * corresponding author e-mail: wangyun0425@163.com
}

\section{H I G H L I G H T S :}

1. Two-sector Model is built to identify and calculate the spillover effects of technological progress on output growth.

2. The industry of one country is divided into two sectors, and technological progress in one sector is added to the production function of the other.

3. The sample data is from China.

4. A very significant spillover effect from the technological progress in equipment manufacturing sector on non-equipment manufacturing sector has been observed.

5. Result of different divisions prove that the production efficiency of equipment manufacturing sector and equipment updating speed of non-equipment manufacturing sector influence the spillover effects.

\begin{tabular}{|c|c|}
\hline Article History & A B S T R A C T \\
\hline $\begin{array}{l}\text { Keywords: } \\
\text { Spillover effect; } \\
\text { Technological progress; } \\
\text { Two-sector model. }\end{array}$ & $\begin{array}{l}\text { As the technology has the nature of public good, industrial technology innovation } \\
\text { activities have positive externalities on related sectors. Two-sector model is built to } \\
\text { identify and calculate the spillover effects of technological progress. Specifically, the } \\
\text { industry is divided into two sectors, and technological progress in one sector is added to } \\
\text { the production function of the other to research the relationship between technological } \\
\text { progress in one sector and output growth of the other. Panel data constituted by time- } \\
\text { series from } 2000 \text { to } 2007 \text { and cross-section data of } 31 \text { provinces in Chinese manufacturing } \\
\text { sectors is used for empirical testing. The conclusion is drawn that there are very } \\
\text { significant spillover effects from the technological progress in equipment manufacturing } \\
\text { sector on non-equipment manufacturing sector. The estimated results of different } \\
\text { divisions prove that the production efficiency of equipment manufacturing sector and } \\
\text { equipment updating speed of non-equipment manufacturing sector influence the spillover } \\
\text { effects. }\end{array}$ \\
\hline $\begin{array}{l}\text { JEL Classification: } \\
\text { O014; 0033; 0041. }\end{array}$ & DOI: http://dx.doi.org/10.18533/jefs.v2i02.55 \\
\hline
\end{tabular}

\subsection{Introduction}

According to industrial linkage theory there are extensive and close economic relations between related industries in the process of economic activities. As the technology has the nature of public good, industrial technology innovation activities have positive externalities. The technical progress in specific industry can not only bring its own economic growth, but also has a technological spillover effect on the related sectors. In terms of the theories,

\footnotetext{
$\diamond$ This paper is funded by National Soft Science Research Program (2013GXS4D108) and MOE (Ministry of Education in China) Project of Humanities and Social Science (13YJC790127).
} 
the technical progress in one sector has a spillover effect on the other sector, promoting the raising of the whole economy. But does this spillover effect really exist?

As far as the studies on spillover effects between sectors, there are two theoretical frameworks. One is the extended one-sector model, mainly used in the study of FDI spillover effect. Its core method is to add the foreign investment as an independent factor into the production function of domestically-funded enterprises. R. Findlay (1978), for instance, constructed a simple dynamic model inspecting the impact of steady-state characteristics on spillover effect, such as the technological gap and the proportion of foreign capital, under the assumption that FDI could increase the local technology through "contagion". Koizumi and Kopecky(1980)considered that the technology involved in the foreign investment had the public goods nature, which brought the additional benefits to the society, and they inspected the impact of FDI on a nation's economic growth by constructing an international capital flow model in long-term. Romer(1990), Aghion(1992)and Barro(1997) analyzed decisive effects of the spillover effects on sustained economic growth from international technology. Rodriguez-Clare (1996) studied the spillover effects between industries of FDI. If the multinational companies' final goods use many intermediate products and there is a big difference between the two countries in the production of intermediate products, the local country will benefit from the spillover effects between industries of FDI. Markusen and Venables (1999) emphasized the dynamic effect on the local productivity generated by FDI through intermediate input and expansion of service requirements, including competitiveness effect and the linkage effect. And a conclusion was reached that multinational companies could boost the local firms producing intermediate product or the final goods.

Another theoretical framework is the two-sector model. To inspect the contribution rate of exports to economic growth, Feder (1983) dichotomized all productive activities into export and non-export sector and made a function to evaluate externality on non-export sector from export sector. By two samples of 19 countries (or regions) and 31 countries (or regions) and the empirical data of 1964-1973, it is verified that the export sector influences nonexport sector through externality and productivity difference effect, and thus indirectly promotes economic growth. Feder's two-sector model was extended by subsequent researchers in different ways. Ram (1985), for example, empirically tested the effects on economic growth from export, using 73 developing countries' data from 1960 to 1977. The effect was not obvious in 1960-1970 but apparent in 1970-1977. Ram (1987) then modified the model to test the effects from export on the export promotion policy, using cross-section and time series data of 88 developing countries. Robert and Alexander (1994) expanded the model into three-sector model of government, export sector and non-export sector. The empirical data of OECD countries showed a significantly positive correlation between government department and export sector, while the spillover effect from government and non-export sector is not obvious. Odedokun (1996) used the two-sector model to examine the effect from financial department on the real economy and economic growth. Based on the findings of 71 developing countries, the effect was especially apparent in low-income countries. Wang $(1999,2000)$ added the expected process of adaptability into the two-sector model and constructed a dynamic two-sector model considering supply and demand to test the causality between financial development and economic growth. The empirical result of Taiwan showed that the external effect from financial department on the real economy was greater than its reverse.

The main problem is whether the technical progress in one sector has positive externality and the degree it spreads into the other sector. This article intends to propose a dynamic framework, which is based on the production function theory and Feder's two-sector model. The inter-sectoral externalities or spillover effects can be derived and estimated. The framework is applied as a prototype to the case of China, a newly industrialized country in East Asia, using panel data constituted by time-series from 2000 to 2007 and cross-section data from 31 provinces. The rest of the article is structured as follows. Section 2 presents the framework of the dynamic two-sector model. Section 3 is the data resources and variable selection. Section 4 is the quantitative analysis and Robustness Test. Section 5 tests the spillover effect of different regions and makes comparison. The last part summarizes concluding remarks.

\section{$2.0 \quad$ The model}

One production function is postulated for each sector. We assume that the whole industry is divided into one sector and the other sector. There exists an externality or spillover effect of one sector onto the production of the other sector. It infers that, while production of one sector is a function of only labor and capital, production of the other sector is a function not only of labor and capital but also of the technical progress in the first sector. In other words, externality arises if an expected technical progress in one sector promotes the output of the other sector. The system described above can now be specified in equations below.

$$
\begin{aligned}
& Y_{t}=E_{t}+N_{t} \\
& K_{t}=K_{E t}+K_{N t} \\
& L_{t}=L_{E t}+L_{N t}
\end{aligned}
$$




$$
\begin{aligned}
& E_{t}=E\left(L_{E t}, K_{E t}\right) \\
& N_{t}=N\left(L_{N t}, K_{N t}, T_{E t}\right)
\end{aligned}
$$

Where,

$Y_{t}=$ aggregate output of the whole industry in period t.

$K_{t}$ and $L_{t}=$ capital and labor input of the whole industry in period $\mathrm{t}$.

$E_{t}$ and $N_{t}=$ aggregate output of one sector and the other sector in period t.

$K_{E t}$ and $K_{N t}=$ physical capital used in the respective sector in period t.

$T_{E t}=$ technical progress in one sector in period $\mathrm{t}$

$L_{E t}$ and $L_{N t}=$ labor force engaged in one sector and the other sector in period t.

By total differential,

$$
\begin{aligned}
& d Y=d E+d N \\
& d K=d K_{E}+d K_{N} \\
& d L=d L_{E}+d L_{N} \\
& d E=E_{L E} * d L_{E}+E_{K E} * d K_{E} \\
& d N=N_{L N} * d L_{N}+N_{K N} * d K_{N}+N_{T_{E}} * d T_{E}
\end{aligned}
$$

And,

$d Y=d E+d N=E_{L E} * d L_{E}+E_{K E} * d K_{E}+N_{L N} * d L_{N}+N_{K N} * d K_{N}+N_{T E} * d T_{E}$

Where, $E_{L E} 、 E_{K E} 、 N_{T E}$ represent the marginal productivities of labor, capital and technical progress in one sector, and $N_{L N} 、 N_{K N}$ stand for the marginal productivities of labor and capital in the other sector.

By recognizing the possible existence of a difference in marginal productivity between the two sectors, we define the following relationship as in Feder (1983): $\theta$ is the productivity differential that makes the ratios deviated from unity.

$$
E_{L E} / N_{L N}=E_{K E} / N_{K N}=1+\theta
$$

By a simple manipulation, Eq. (11) can be derived as shown below:

$$
d Y=N_{L N} * d L+N_{K N} * d K+\frac{\theta}{1+\theta} * d E+N_{T_{E}} * d T_{E}
$$

Assuming that the spillover elasticity on the other sector from the technical progress in one sector $\left(T_{E}\right)$ is constant, so,

$$
N_{t}=N\left(L_{N t}, K_{N t}, T_{E t}\right)=T_{E}^{\lambda} \varphi\left(L_{N t}, K_{N t}\right)
$$

From Eq. (14),

$$
N_{T E}=\lambda * \frac{N}{T_{E}}
$$

By substituting Eq. (15) into Eq. (13), it can now be rewritten as,

$$
d Y=N_{L N} * d L+N_{K N} * d K+\frac{\theta}{1+\theta} * d E+\lambda * \frac{N}{T_{E}} * d T_{E}
$$

Divided by $Y$, it can further be written as,

$$
\frac{d Y}{Y}=N_{L N} * \frac{L}{Y} * \frac{d L}{L}+N_{K N} * \frac{K}{Y} * \frac{d K}{K}+\frac{\theta}{1+\theta} * \frac{E}{Y} * \frac{d E}{E}+\lambda * \frac{N}{Y} * \frac{d T_{E}}{T_{E}}
$$

Where, $\frac{d L}{L}$ and $\frac{d K}{K}$ indicate the growth rates of labor and capital respectively, $\frac{E}{Y} * \frac{d E}{E}$ indicates the direct contribution to the whole industry from one sector. $\frac{N}{Y} * \frac{d T_{E}}{T_{E}}$ shows that the technical progress in one sector promotes the whole industrial economy through their elasticity. 
The technical progress in one sector is measured in Cobb-Douglas production function, which is regarded as a basic method to measure the technical level or technical progress.

$$
Y=A K^{\alpha} L^{\beta}
$$

Where, $Y$ indicates the output, $K$ and $L$ are the input of capital and labor, $\alpha$ and $\beta$ indicate the output elasticity of capital and labor, $A$ is the technical level, i.e. the Total Factor Productivity(TFP).Given that $A=\frac{Y}{K^{\alpha} L^{\beta}}$, the formula of technical progress in one sector is

$$
T_{E}=\frac{E}{K_{E}^{\alpha} L_{E}^{\beta}}
$$

In general, there are two forms of the production function: constant returns to scale $(\alpha+\beta=1)$ and variable returns to scale $(\alpha+\beta \neq 1)$.Under the assumption of constant returns to scale, i.e. $\alpha+\beta=1$.Eq. (19) can be converted to

$$
T_{E}=\frac{E / L_{E}}{\left(K_{E} / L_{E}\right)^{\alpha}}
$$

So,

$$
\frac{d T_{E}}{T_{E}}=\frac{d E / L_{E}}{E / L_{E}}-\alpha * \frac{d K / L_{E}}{K_{E} / L_{E}}
$$

Substituting Eq. (21) into Eq. (17),

$$
\frac{d Y}{Y}=N_{L_{N}} * \frac{L}{Y} * \frac{d L}{L}+N_{K N} * \frac{K}{Y} * \frac{d K}{K}+\frac{\theta}{1+\theta} * \frac{E}{Y} * \frac{d E}{E}+\lambda * \frac{N}{Y} *\left(\frac{d E / L_{E}}{E / L_{E}}-\alpha * \frac{d K_{E} / L_{E}}{K_{E} / L_{E}}\right)
$$

To compute $\frac{N}{Y} *\left(\frac{d E / L_{E}}{E / L_{E}}-\alpha * \frac{d K_{E} / L_{E}}{K_{E} / L_{E}}\right)$, it needs to determine the output elasticity coefficient, $\alpha$. There are mainly three methods: empirical estimation, ratio method and method of regression. This article uses ratio method to measure the output elasticity. As the capital and labor input may have the same tendency over time, so there is serious co-linearity between variables. To lessen this problem, the variables are usually processed in average form. So the formula is derived from Eq. (18),

$$
\ln \frac{Y}{L}=\ln A+\alpha * \ln \frac{K}{L}
$$

Thus, the formula of output elasticity of one sector is

$$
\ln \frac{E}{L_{E}}=C+\alpha * \ln \frac{K_{E}}{L_{E}}+e
$$

Decomposing $\frac{N}{Y} *\left(\frac{d E / L_{E}}{K_{E} / L_{E}}-\alpha * \frac{d K_{E} / L_{E}}{K_{E} / L_{E}}\right)$ of Eq. (22),

$$
\frac{d Y}{Y}=N_{L_{N}} * \frac{L}{Y} * \frac{d L}{L}+N_{K N} * \frac{K}{Y} * \frac{d K}{K}+\frac{\theta}{1+\theta} * \frac{E}{Y} * \frac{d E}{E}+\lambda * \frac{N}{Y} * \frac{d E / L_{E}}{E / L_{E}}+(-\alpha) * \lambda * \frac{N}{Y} * \frac{d K_{E} / L_{E}}{K_{E} / L_{E}}
$$

Replaced $N_{L_{N}} * \frac{L}{Y}, N_{K_{N}} * \frac{K}{Y}, \frac{\theta}{1+\theta}, \lambda 、(-\alpha) * \lambda$ of Eq.(25) by $C_{1}, C_{2}, C_{3}, C_{4}, C_{5}$ and $\frac{d Y}{Y}$ 、 $\frac{d L}{L} 、 \frac{d K}{K}, \frac{E}{Y} * \frac{d E}{E} 、 \frac{N}{Y} * \frac{d E / L_{E}}{E / L_{E}}, \frac{N}{Y} * \frac{d K_{E} / L_{E}}{K_{E} / L_{E}}$ by $g i, g l, g k 、 c e, c e t n 1, c e k / l n 1$, Eq.(25) is rewritten as: 


$$
g i=C_{1} * g l+C_{2} * g k+C_{3} * c e+C_{4} * c e t n 1+C_{5} * c e k / l n 1
$$

So, Eq. (26) is the elasticity formula to measure the spillover effect of technical progress in one sector under the assumption of constant returns to scale.

As for the assumption of variable returns to scale, i.e. $\alpha+\beta \neq 1$, firstly, Eq. (19) is converted in the average form:

$$
T_{E}=\frac{E / L_{E}}{\left(K_{E} / L_{E}\right)^{\alpha} * L_{E}{ }^{(\alpha+\beta-1)}}
$$

So,

$$
\frac{d T_{E}}{T_{E}}=\frac{d E / L_{E}}{E / L_{E}}-\alpha * \frac{d K_{E} / L_{E}}{K_{E} / L_{E}}-(\alpha+\beta-1) * \frac{d L_{E}}{L_{E}}
$$

Substituting Eq. (28) into Eq. (17),

$$
\frac{d Y}{Y}=N_{L_{N}} * \frac{L}{Y} * \frac{d L}{L}+N_{K_{N}} * \frac{K}{Y} * \frac{d K}{K}+\frac{\theta}{1+\theta} * \frac{E}{Y} * \frac{d E}{E}+\lambda * \frac{N}{Y} *\left[\frac{d E / L_{E}}{E / L_{E}}-\alpha * \frac{d K_{E} / L_{E}}{K_{E} / L_{E}}-(\alpha+\beta-1) * \frac{d L_{E}}{L_{E}}\right]
$$

In the same way, to compute $\frac{N}{Y} *\left[\frac{d E / L_{E}}{E / L_{E}}-\alpha * \frac{d K_{E} / L_{E}}{K_{E} / L_{E}}-(\alpha+\beta-1) * \frac{d L_{E}}{L_{E}}\right]$, it needs to determine $\alpha$ and $(\alpha+\beta-1)$

Derived from Eq. (18),

$$
\ln E / L_{E}=C+\alpha * \ln K_{E} / L_{E}+(\alpha+\beta-1) \ln L_{E}+e
$$

Decomposing $\frac{d E / L_{E}}{E / L_{E}}-\alpha * \frac{d K_{E} / L_{E}}{K_{E} / L_{E}}-(\alpha+\beta-1) * \frac{d L_{E}}{L_{E}}$ of Eq. (30),

$$
\begin{aligned}
\frac{d Y}{Y}= & N_{L_{N}} * \frac{L}{Y} * \frac{d L}{L}+N_{K_{N}} * \frac{K}{Y} * \frac{d K}{K}+\frac{\theta}{1+\theta} * \frac{E}{Y} * \frac{d E}{E}+\lambda * \frac{N}{Y} * \frac{d E / L_{E}}{E / L_{E}}+(-\alpha) * \lambda * \frac{N}{Y} * \frac{d K_{E} / L_{E}}{K_{E} / L_{E}} \\
& +(1-\alpha-\beta) * \lambda * \frac{N}{Y} * \frac{d L_{E}}{L_{E}}
\end{aligned}
$$

Replaced $\frac{N}{Y} * \frac{d E / L_{E}}{E / L_{E}}, \frac{N}{Y} * \frac{d K_{E} / L_{E}}{K_{E} / L_{E}}, \frac{N}{Y} * \frac{d L_{E}}{L_{E}}$ of Eq.(31) bycetn2,cek/ln2、ce $\ln$ and $(-\alpha) * \lambda$ 、 $(1-\alpha-\beta) * \lambda$ by $C_{5} 、 C_{6}$, Eq.(31) is rewritten as:

$$
g i=C_{1} * g l+C_{2} * g k+C_{3} * c e+C_{4} * c e t n 2+C_{5} * c e k / l n 2+C_{6} * c e \ln
$$

So, Eq. (32) is the elasticity formula to measure the spillover effect of technical progress in one sector under the assumption of variable returns to scale.

By knowing the possibility of existence of simultaneity in generating externalities, the follow two equations will be treated as a system of equations in the estimation procedure, where $\mu$ is disturbance terms. So, eq. (I) and Eq.(II) will be the basic model for empirical analysis.

$$
\begin{aligned}
& g i=C_{1} * g l+C_{2} * g k+C_{3} * c e+C_{4} * c e t n 1+C_{5} * c e k / l n 1+\mu \\
& g i=C_{1} * g l+C_{2} * g k+C_{3} * c e+C_{4} * c e t n 2+C_{5} * c e k / l n 2+C_{6} * c e \ln +\mu
\end{aligned}
$$

\subsection{Data construction and resources}


In empirical application of the two-sector model to the case of China, we confine our study to exam the relationship between the equipment manufacturing sector and non-equipment manufacturing sector. Equipment manufacturing sector is to provide the technical equipments to other sectors for reproduction. All variables are annual observations from 2000 to 2007. The data used are from above-designated-size enterprises in 31 provinces in China $^{2}$.The productions of equipment manufacturing sector defined in this article consist of steel products, electronics products and investment category products of weapon industry, which all belong to the seven categories and 185 sub-categories of Metal Product Industry, General Equipment Manufacturing Industry, Special Equipment Manufacturing Industry, Transport Equipment Manufacturing Industry, Electrical Equipment and Equipment Manufacturing Industry, Electronic and Telecommunication Equipment industry, Instruments and Office Stationeries Manufacturing Industry. The data used in this article is integrated from the above seven industries.

The output variables are deflated using the Producer's Price Index for Manufactured Products and expressed in constant prices as of the year 2000. As for the capital input, there are mainly five indicators in the existing literature.(1) Fixed Assets Investment in the statistical data;(2)Accumulated Amount;(3) Net Value of fixed assets and Average Balance of current assets of all the apartments;(4)Net Capital Stock and Net Fixed Capital Stock in National Economic Accounting;(5) capital services supplied. Since the Net Fixed Assets is frequently used to test the technical progress contribution ratio, the annual net value of net fixed assets is used to indicate the capital input. The input variables are deflated using the Price Indices of Investment in fixed assets and Perpetual Inventory Method (PIM) and also expressed in constant prices as of the year 2000.The formula is:

$K_{E_{t}}=I_{t}+(1-\delta) K_{E_{t-1}}$

where, $K_{E_{t}}$ and $K_{E_{t-1}}$ represent the capital stock of equipment manufacturing sector in period t and t-1, $I_{t}$ is the capital input, $\delta$ is the rate of depreciation of equipments. From Eq. (33), the key to test the capital stock is to determine the rate of depreciation and the capital stock in base period 2000. Many Chinese scholars use different methods to measure the depreciation rate. Such as, Huang Yongfeng evaluated the rate of depreciation of equipments as $17 \%$, assuming that the life span is 16 years, while Zhang Jun assumed 20 years and computed the rate as $15 \%$.This article chooses $17 \%$ as the rate of depreciation. As for the capital stock in base period, in the existing literature, the capital input of base period is divided by 10\% (Huang Yongfeng, 2002), which is used in this article. As for the labor input, there are three indicators home and abroad.(1) laborer number, i.e. the employed number;(2)the whole work time, i.e. average labor time multiplies laborer number; (3) Compensation of Laborers. As the laborer number can simply indicate the labor input scale and it has no price-adjusting problem, this article uses average annual employed number to represent the labor input.

\begin{tabular}{|c|c|c|c|c|c|}
\hline \multicolumn{6}{|c|}{ Table 01: Variable symbols and their descriptive statistics } \\
\hline & Symbol & mean & SD & Maximum & Minimum \\
\hline \multirow{5}{*}{$\begin{array}{l}\text { Indicators } \\
\text { of output } \\
\text { elasticity }\end{array}$} & $E / L_{E i, t}$ & 27.56151 & 17.86246 & 98.16090 & 1.821429 \\
\hline & $K / L_{E i, t}$ & 61.13383 & 47.73957 & 446.4970 & 22.14120 \\
\hline & $E_{i, t}$ & 2297.335 & 4032.037 & 28535.92 & 0.510000 \\
\hline & $K_{E i, t}$ & 2974.478 & 3074.644 & 13749.69 & 9.200000 \\
\hline & $L_{E i, t}$ & 63.25300 & 91.12457 & 621.0000 & 0.280000 \\
\hline \multirow{8}{*}{$\begin{array}{l}\text { Indicators } \\
\text { of technical } \\
\text { spillover } \\
\text { effect }\end{array}$} & $g i_{i, t}$ & 0.217539 & 0.087628 & 0.471560 & 0.002427 \\
\hline & $g l_{i, t}$ & 0.030439 & 0.079340 & 0.344415 & -0.339350 \\
\hline & $g k_{i, t}$ & -0.002052 & 0.043746 & 0.123465 & -0.064552 \\
\hline & $c e_{i, t}$ & 0.063236 & 0.052927 & 0.244071 & -0.018123 \\
\hline & cetn $1_{i, t-1}$ & 0.138109 & 0.145233 & 1.595893 & -0.056381 \\
\hline & $\operatorname{cetn} 2 i, t-1$ & 0.134021 & 0.094487 & 0.813949 & -0.174805 \\
\hline & $c e k / l \mathrm{n}_{i, t-1}$ & 0.029146 & 0.635357 & 7.982386 & -0.386556 \\
\hline & $c e \ln { }_{i, t-1}$ & 0.004418 & 0.102905 & 0.704140 & -0.470816 \\
\hline
\end{tabular}

\footnotetext{
2 The data are published by National Bureau of Statistics from China Statistical Yearbook, Sta. Almanac of Chinese Industrial Economy and China's Economic Census Yearbook.
} 
In the two-sector model, to test the spillover elasticity, the main variables are $g i, g l 、 g k 、 c e$, $\operatorname{cetn}_{i}$ (i.e.cetn1 and cetn2), standing for the growth rate of output value, labor input, capital input of enterprises above designated size, and the direct contribution from equipment manufacturing sector and technical spillover on non-equipment manufacturing sector from equipment manufacturing sector. From the derivation in section 2, the direct contribution is each variable divided by total output multiplies its own growth rate. The growth rate of labor input is these enterprises' average annual laborer number, while the growth rate of capital input is these enterprises' average annual net fixed assets. Due to the time lag in technical spillover, the variables in empirical model which are related to ${ } e t n_{i}$ all use lagged variables. In addition, the measurement of capital variable and capital stock in the above process is the same as that of capital stock in output elasticity of equipment manufacturing sector. Variable symbols and a detailed description of data are given in Table 01.

\subsection{Empirical analysis}

This article uses panel data of 31 provinces in China (except for Hong Kong, Macao and Taiwan) from 2000 to 2007.The regression empirically tests the spillover effect of technical progress in equipment manufacturing sector on non-equipment manufacturing sector.

\subsection{The estimation of spillover elasticity}

To estimate the spillover effect of technical progress, the output elasticity of capital and labor input in equipment manufacturing sector is not necessary. But to analyze the production characteristics of equipment manufacturing sector, this article calculates the output elasticity, and the results are tabulated in Table 2. The results show that $\alpha$, the output elasticity of capital input and $\beta$, the output elasticity of labor input are both very significant under the assumptions of constant returns to scale and variable returns to scale. And $\alpha$ is 0.596 and 0.897 while $\beta$ is 0.404 and 0.408 , which indicate that the contribution from capital to output is greater than that from labor.

\begin{tabular}{|c|c|c|c|}
\hline \multicolumn{4}{|c|}{ Table 02: Results of output elasticity of equipment manufacturing sector } \\
\hline Assumptions & $\alpha+\beta=1$ & & \\
\hline Constant and output elasticity & $\alpha$ & $\alpha$ & $\alpha+\beta-1$ \\
\hline Constant & $\begin{array}{c}0.755294 \\
(0.992545)\end{array}$ & \multicolumn{2}{|c|}{$\begin{array}{c}-1.457048^{* * *} \\
(-3.228586)\end{array}$} \\
\hline Output elasticity & $\begin{array}{c}0.596300^{* * *} \\
(3.093380)\end{array}$ & $\begin{array}{c}0.896777^{* * *} \\
(7.531433)\end{array}$ & $\begin{array}{c}0.304896^{* * *} \\
(43.13345)\end{array}$ \\
\hline Ad- $R^{2}$ & 0.356054 & \multicolumn{2}{|c|}{0.731690} \\
\hline F-value & 16.13634 & \multicolumn{2}{|c|}{67.35778} \\
\hline Prob(F-statistic) & 0.000000 & \multicolumn{2}{|c|}{0.000000} \\
\hline
\end{tabular}

As the elasticity coefficient difference of input factors is highly related to their utilization, some scholars have reached the conclusions that capital elasticity coefficient of heavy industry and capital-intensive industry is greater than that of light industry and labor-intensive industry (Wang Dewen, 2004).So Chinese equipment manufacturing sector is a typical capital-intensive industry, in which capital is usually combined with relevant technology, having a significant effect on economic growth of the industry. In addition, under the assumption of variable returns to scale, $\alpha+\beta-1=0.305>0$, so it belongs to increasing returns to scale.

Table 03: Empirical results of spillover effect of technical progress in equipment manufacturing sector

\begin{tabular}{|c|c|c|c|}
\hline \multirow{2}{*}{\multicolumn{2}{|c|}{ Variables }} & \multicolumn{2}{|c|}{ Assumptions } \\
\hline & & $\alpha+\beta=1$ & $\alpha+\beta \neq 1$ \\
\hline \multicolumn{2}{|c|}{ Constant } & $\begin{array}{c}0.149459^{* * *} \\
(18.06594)\end{array}$ & $\begin{array}{c}0.151511^{* * *} \\
(18.51031)\end{array}$ \\
\hline \multicolumn{2}{|c|}{$g l_{i, t}$} & $\begin{array}{c}0.296611^{* * *} \\
(4.148063)\end{array}$ & $\begin{array}{c}0.296179^{* * *} \\
(4.164246)\end{array}$ \\
\hline \multicolumn{2}{|c|}{$g k_{i, t}$} & $\begin{array}{c}0.620371^{* * *} \\
(4.265687)\end{array}$ & $\begin{array}{c}0.596612^{* * *} \\
(3.740337)\end{array}$ \\
\hline \multicolumn{2}{|c|}{$c e_{i, t}$} & $\begin{array}{c}0.520703^{* * *} \\
(5.393829)\end{array}$ & $\begin{array}{c}0.512122^{* * *} \\
(5.583881)\end{array}$ \\
\hline $\operatorname{cetn}_{i, t-1}$ & $\operatorname{cetn} 1_{i, t-1}$ & $\begin{array}{c}0.158045^{* * *} \\
(3.886001)\end{array}$ & \\
\hline
\end{tabular}




\begin{tabular}{|c|c|c|c|}
\hline \multirow{3}{*}{$c e k / l \mathrm{n}_{i, t-1}$} & \multirow{3}{*}{$\begin{array}{l}\text { cetn } 2_{i, t-1} \\
\text { cek } / \ln 1_{i, t-1} \\
\text { cek } / \ln 2_{i, t-1}\end{array}$} & & \multirow[t]{2}{*}{$\begin{array}{c}0.150723^{* * *} \\
(3.840917)\end{array}$} \\
\hline & & $\begin{array}{c}-0.276398^{* * *} \\
(-3.522674)\end{array}$ & \\
\hline & & & $\begin{array}{l}-0.237374^{* *} \\
(-2.465686)\end{array}$ \\
\hline \multicolumn{2}{|c|}{$c e \ln i, t-1$} & & $\begin{array}{c}0.033156 \\
(0.548783)\end{array}$ \\
\hline \multicolumn{2}{|c|}{ Ad-R ${ }^{2}$} & 0.617931 & 0.615606 \\
\hline \multicolumn{2}{|c|}{ F-value } & 27.03900 & 24.44005 \\
\hline \multicolumn{2}{|c|}{ Prob(F-statistic) } & 0.000000 & 0.000000 \\
\hline
\end{tabular}

Fixed Effects Model is used to estimate the spillover elasticity of equipment manufacturing sector. Considering the possible heteroskedasticity of cross section, consistent covariance matrix of White heteroskedasticity is used to modify the model so as to have the robust t-statistics results. The results of parameters are in Table 3.

\subsection{Results analysis}

The estimated results show that the signs of all variable coefficients are as expected. The Adjusted R-squared are all above 0.61 and the equation's goodness-of-fit is comparatively high, passing the test of significance. Under the assumptions of constant returns to scale and variable returns to scale, the results are almost the same.

The estimated coefficient of cetn, the technical spillover effect from equipment manufacturing sector on nonequipment manufacturing sector, is positive at the level of $1 \%$ under the two assumptions, which proves the existence of the spillover effect. Meanwhile, the estimated coefficient of $c e$ is significant at the level of $1 \%$, indicating the direct contribution of equipment manufacturing sector to the whole industry is very apparent. The estimated values are 0.51 and 0.52 , showing that the impetus function on the whole industry from equipment manufacturing sector is very great. $C_{3}=\theta /(1+\theta)>0, \theta>0$ represents the marginal productivity of equipment manufacturing sector is higher than that of non-equipment manufacturing sector. Due to the two assumptions, the parameter estimations are different and the results have differences. The concrete explanation of the empirical results is as follows:

(1) Assuming constant returns to scale, the estimated results of the spillover effect of technical progress in equipment manufacturing sector is significant at the level of $1 \%$ and the spillover elasticity is $15.8 \%$. The reasons that the spillover elasticity is not very great lie in two sides. One is the comparatively low technical level and production efficiency of Chinese equipment manufacturing sector. The other is the slow equipment updating speed of non-equipment manufacturing sector. The net value of fixed assets (including the production equipments) from 2001 to 2004 increases at the rate of $-6.8 \%,-5.4 \%,-4.0 \%,-1.6 \%$. After four years of negative growth, the growth rate becomes to be positive from 2005 to 2007 , but only at the level of $0.2 \%, 2.8 \%$ and $4.4 \%$.So the average growth rate between 2001 and 2007 is $-1.5 \%$. Even considering the depreciation, the equipment updating speed is still slow so that non-equipment manufacturing sector can not enjoy the spillover effect from equipment manufacturing sector, which is named "threshold effect" in the study of spillover effect of FDI by Borenztein (1998).The threshold effect means that only when the factors affecting the spillover effect are above the "threshold" can the effect be apparent. In the conditions of limited technical level of equipment manufacturing sector and the slow speed of equipment updating in non-equipment manufacturing sector, the factors do not reach the "threshold", so the spillover effect is not apparent.

While the equipment manufacturing sector has a notable driving force on the whole industry and the direct contribution $C_{3}$ is $52 \%$. $C_{3}=\theta /(1+\theta), \theta=1.08$ shows that the marginal output in equipment manufacturing sector is $108 \%$ higher than that of non-equipment manufacturing sector. The contribution of labor to industrial economic growth is about $30 \%$ and the growth of investments in fixed assets to the industry is $62 \%$.So Chinese industrial economic growth owes to the investments in fixed assets to a large extent, reflecting the current situation of investment-lead economic growth.

(2) Assuming variable returns to scale, the parameter estimation of technical spillover from equipment manufacturing sector is still significant at the level of $1 \%$ and the spillover elasticity is $15.1 \%$, which is close to that of the variable returns to scale. And $C_{3}=\theta /(1+\theta)=51.2 \%, \theta=1.04$ indicates that the marginal output in equipment manufacturing sector is $104 \%$ higher than that of other industries. So the rapid development of equipment manufacturing sector will push Chinese economic growth. In addition, the contribution of labor to 
the growth of the whole industry is about $30 \%$ and the contribution of increasing investments in fixed assets is $60 \%$, which also can prove Chinese situation of investment-lead economic growth.

\subsection{Robustness test}

In the test of the capital stock of investments in fixed assets, the depreciation rate is still in discussion and different rates will influence the technical spillover elasticity. To get the robust results, this article not only uses $17 \%$ as the depreciation rate, which is usually used in the test of capital stock in manufacturing industries, but also $10 \%$ assumed by GongLiutang (2004) and 5\% assumed by Perkins (1998). The empirical results are tabulated in Table 4.

From the empirical results, the spillover elasticity is apparently positive under different depreciation rates. If the depreciation rate is $10 \%$, the elasticity is $15.3 \%$ and $13.3 \%$, and if the rate is $5 \%$, the elasticity is $8.6 \%$ and $10.1 \%$. Additionally, both the equation and the variables are of great significance, passing robustness test. The results prove that the technical progress in equipment manufacturing sector can drive the output growth of non-equipment manufacturing sector.

Based on the results of parameter estimation and robustness test, no matter the depreciation rates and the assumptions of returns scale, there exists a positive relation between the technical progress in equipment manufacturing sector and the output of non-equipment manufacturing sector. The driving force from equipment manufacturing sector to the whole industrial economy is certain and great.

\begin{tabular}{|c|c|c|c|c|}
\hline $\begin{array}{l}\text { Depreciation rate of } \\
\text { investment stock of fixed }\end{array}$ & \multicolumn{2}{|c|}{ Depreciation rate $=10 \%$} & \multicolumn{2}{|c|}{ Depreciation rate $=5 \%$} \\
\hline Assumptions & $\begin{array}{l}\text { Constant returns } \\
\text { to scale }\end{array}$ & $\begin{array}{l}\text { Variable returns to } \\
\text { scale }\end{array}$ & $\begin{array}{l}\text { Constant returns } \\
\text { to scale }\end{array}$ & Variable returns to scale \\
\hline constant & $\begin{array}{c}0.135391^{* * *} \\
(25.27097)\end{array}$ & $\begin{array}{c}0.138728^{* * *} \\
(24.48100)\end{array}$ & $\begin{array}{c}0.156990^{* * *} \\
(12.44104)\end{array}$ & $\begin{array}{c}0.167870^{* * *} \\
(14.38746)\end{array}$ \\
\hline$g l_{i, t}$ & $\begin{array}{c}0.307312^{* * *} \\
(4.431512)\end{array}$ & $\begin{array}{c}0.305326^{* * *} \\
(4.451815)\end{array}$ & $\begin{array}{c}0.281415^{* * *} \\
(3.597260)\end{array}$ & $\begin{array}{c}0.270247^{* * *} \\
(3.351775)\end{array}$ \\
\hline$g k_{i, t}$ & $\begin{array}{c}0.679423^{* * *} \\
(3.851194)\end{array}$ & $\begin{array}{c}0.622658^{* * *} \\
(3.309138)\end{array}$ & $\begin{array}{c}0.460283^{* * *} \\
(4.341735)\end{array}$ & $\begin{array}{c}0.398548^{* * *} \\
(3.566382)\end{array}$ \\
\hline$c e_{i, t}$ & $\begin{array}{c}0.485646^{* * *} \\
(4.897941)\end{array}$ & $\begin{array}{c}0.478163^{* * *} \\
(5.193663)\end{array}$ & $\begin{array}{c}0.653020^{* * *} \\
(7.485655)\end{array}$ & $\begin{array}{c}0.575191^{* * *} \\
(7.582181)\end{array}$ \\
\hline $\operatorname{cetn}_{i, t-1}$ & $\begin{array}{c}0.153762^{* * *} \\
(3.605653)\end{array}$ & & $\begin{array}{c}0.086172^{* * *} \\
(3.060826)\end{array}$ & \\
\hline $\operatorname{cetn} 2_{i, t-1}$ & & $\begin{array}{c}0.133004^{* * *} \\
(3.168456)\end{array}$ & & $\begin{array}{c}0.100589 * * * \\
(3.190092)\end{array}$ \\
\hline$c e k / \ln 2 i, t-1$ & $\begin{array}{c}-0.241281^{* * *} \\
(-3.272485)\end{array}$ & $\begin{array}{c}-0.149677 \\
(-1.547925)\end{array}$ & $\begin{array}{c}-0.248939^{* * *} \\
(-2.985657)\end{array}$ & $\begin{array}{l}-0.151430^{* *} \\
(-2.256009)\end{array}$ \\
\hline$c e \ln i, t-1$ & & $\begin{array}{c}0.080840 \\
(1.238122)\end{array}$ & & $0.113086^{* *}(2.133140)$ \\
\hline Ad- $R^{2}$ & 0.611910 & 0.610486 & 0.620738 & 0.624425 \\
\hline F-value & 26.38520 & 23.93960 & 27.35085 & 25.33413 \\
\hline Prob(F-statistic) & 0.000000 & 0.000000 & 0.000000 & 0.000000 \\
\hline
\end{tabular}

\subsection{Influences of production efficiency and equipment updating speed}

In the empirical test, it assumes that the spillover effect is the same in all the areas. But actually, factors like the production efficiency of equipment manufacturing sector and the equipment updating speed of non-equipment manufacturing sector affect the spillover effect. To examine the above two factors' influence, the areas are divided into groups to test the elasticity under different constraint conditions. And the depreciation rate is assumed as $17 \%$ in consideration of space and error.

\subsection{Divisions by production efficiency}

This article uses per capita aggregate industrial output value to represent the production efficiency. If the value is above 25.88 billion Yuan per million people (25.88 is the average amount of all provinces in China from 2000 to 2007), the area belongs to the high production efficiency group, and the others belong to the low efficiency group. According to this standard, the high efficiency group includes Beijing, Tianjin, Liaoning, Jilin, Shanghai, Jiangsu, 
Zhejiang, Anhui, Fujian, Shandong, Hubei, Guangdong, Guangxi, Chongqing. To get more accurate results, four provinces (Henan, Hunan, Hainan and Xizang) of insufficient data are excluded. The results of this division are as follows:

\begin{tabular}{|c|c|c|c|c|}
\hline \multicolumn{5}{|c|}{ Table 05: The results of spillover effect according to the division by production efficiency } \\
\hline Standard & \multicolumn{4}{|c|}{ Production efficiency of equipment manufacturing sector } \\
\hline Assumptions & \multicolumn{2}{|c|}{ Constant returns to scale } & \multicolumn{2}{|c|}{ Variable returns to scale } \\
\hline Variables & High efficiency & Low efficiency & High efficiency & Low efficiency \\
\hline Constant & $\begin{array}{c}0.118698^{* * *} \\
(11.60585)\end{array}$ & $\begin{array}{c}0.162099 * * * \\
(17.92904)\end{array}$ & $\begin{array}{c}0.108812^{* * *} \\
(10.57209)\end{array}$ & $\begin{array}{c}0.160187^{* * *} \\
(18.09462)\end{array}$ \\
\hline$g l_{i, t}$ & $\begin{array}{c}0.305953^{* * *} \\
(3.523704)\end{array}$ & $\begin{array}{c}0.382321^{* * *} \\
(7.058146)\end{array}$ & $\begin{array}{c}0.283416^{* * *} \\
(3.450943)\end{array}$ & $\begin{array}{c}0.348141^{* * *} \\
(4.063749)\end{array}$ \\
\hline$g k_{i, t}$ & $\begin{array}{c}0.090900 \\
(0.371820)\end{array}$ & $\begin{array}{c}1.638597^{* * *} \\
(7.968534)\end{array}$ & $\begin{array}{c}0.550667^{*} \\
(1.774505)\end{array}$ & $\begin{array}{c}1.594833^{* * *} \\
(6.713383)\end{array}$ \\
\hline$c e_{i, t}$ & $\begin{array}{c}0.593972 * * * \\
(7.442753)\end{array}$ & $\begin{array}{c}1.273574^{* * *} \\
(4.128342)\end{array}$ & $\begin{array}{c}0.682682^{* * *} \\
(9.581417)\end{array}$ & $\begin{array}{c}1.372924^{* * *} \\
(5.384346)\end{array}$ \\
\hline $\operatorname{cetn}_{i, t-1}$ & $\begin{array}{c}0.263109^{* * *} \\
(3.599043)\end{array}$ & $\begin{array}{c}0.038168^{*} \\
(1.726999)\end{array}$ & $\begin{array}{c}0.205603^{* * *} \\
(3.904901)\end{array}$ & $\begin{array}{c}0.096144^{*} \\
(1.764808)\end{array}$ \\
\hline$c e k / \ln 2 i, t-1$ & $\begin{array}{c}-0.343963^{* * *} \\
(-5.513977)\end{array}$ & $\begin{array}{c}-0.001186 \\
(-0.494497)\end{array}$ & $\begin{array}{c}-1.235567^{* * *} \\
(-5.010599)\end{array}$ & $\begin{array}{c}-0.065558 \\
(-0.462209)\end{array}$ \\
\hline$c e \ln i, t-1$ & & & $\begin{array}{c}-0.746008^{* * *} \\
(-4.546330)\end{array}$ & $\begin{array}{c}0.113482 \\
(1.305592)\end{array}$ \\
\hline Ad- $\mathrm{R}^{2}$ & 0.747839 & 0.575531 & 0.775207 & 0.668561 \\
\hline F-value & 25.61542 & 11.44033 & 27.02073 & 15.12004 \\
\hline Prob(F-statistic) & 0.000000 & 0.000000 & 0.000000 & 0.000000 \\
\hline
\end{tabular}

According to the empirical results, after the areas are divided by production efficiency, the spillover elasticity of technical progress changes apparently. Under the assumption of constant returns to scale, the elasticity is $26.31 \%$ in the areas of high production efficiency and $3.81 \%$ in the areas of low efficiency, making a difference of almost $23 \%$.Under the assumption of variable returns to scale, the elasticity is $20.56 \%$ in the areas of high production efficiency and $9.61 \%$ in the areas of low efficiency, making a difference of almost $11 \%$.These two conditions show that the production efficiency of equipment manufacturing sector has a great impact on the technical spillover effect and the higher the production efficiency, more apparent the effect.

\subsection{Divisions by equipment updating speed}

This article uses the growth rate of fixed assets investment (FAI) stock to represent the equipment updating speed in non-equipment manufacturing sector. If the average growth rate is above $-0.01189(-0.01189$ is the average value of the growth rate in all provinces in China from 2000 to 2007), the area belongs to high updating speed group, and the others all belong to the slow updating speed group. According to this standard, the high updating speed group includes Hebei, Shanxi, NeiMenggu, Jiangsu, Zhejiang, Fujian, Shandong, Henan, Hubei, Hainan, Guizhou, Shaanxi, Ningxia. Similarly, and provinces of insufficient data like Henan, Hunan, Hainan, Xizang are excluded. Table 6 shows the empirical results.

According to this kind of division, the technical spillover elasticity of equipment manufacturing sector still has the difference. Under the assumption of constant returns to scale, the elasticity is about $23.47 \%$ in the areas of high equipment updating speed in non-equipment manufacturing sector, and $9.89 \%$ in the areas of low updating speed. Under the assumption of variable returns to scale, the elasticity is about $34 \%$ in the areas of high updating speed, and $12.88 \%$ in the areas of slow updating speed, making a difference of almost $21 \%$. These two conditions both indicate that the equipment updating speed of non-equipment manufacturing sector has a great impact on the technical spillover effect of equipment manufacturing sector. And the effect is more apparent in the areas of high updating speed.

Table 06: The results of spillover effect according to the division of equipment updating speed in non-equipment manufacturing sector

\begin{tabular}{|c|c|c|c|c|}
\hline \multicolumn{5}{|c|}{ ion-equipment manufacturing sector } \\
\hline Assumptions & \multicolumn{2}{|c|}{ Constant returns to scale } & \multicolumn{2}{|c|}{ Variable returns to scale } \\
\hline Variables & High speed & Low speed & High speed & Low speed \\
\hline Constant & $\begin{array}{c}0.151916^{* * *} \\
(5.592464)\end{array}$ & $\begin{array}{c}0.161357^{* * *} \\
(12.42255)\end{array}$ & $\begin{array}{c}0.155607^{* * *} \\
(6.261152)\end{array}$ & $\begin{array}{c}0.149129^{* * *} \\
(20.04638)\end{array}$ \\
\hline$g l_{i, t}$ & $\begin{array}{c}0.482262^{* * *} \\
(5.629162)\end{array}$ & $\begin{array}{c}0.162041 \\
(1.077186)\end{array}$ & $\begin{array}{c}0.409575^{* * *} \\
(6.918856)\end{array}$ & $\begin{array}{c}0.159338 \\
(1.038501)\end{array}$ \\
\hline
\end{tabular}




\begin{tabular}{c|c|c|c|c}
\hline$g k_{i, t}$ & 0.375315 & $1.136149^{* *}$ & 0.015347 & $1.346115^{*}$ \\
$\left(c e_{i, t}\right.$ & $(1.087291)$ & $(2.052745)$ & $(0.049735)$ & $(2.301717)$ \\
\hline \multirow{2}{*}{$c e t n 4 i, t-1$} & 0.404295 & $0.622331^{* * *}$ & 0.285508 & $0.715618^{* * *}$ \\
& $(1.098040)$ & $(6.878039)$ & $(1.231791)$ & $(10.75322)$ \\
\hline$c e k / \ln 2 i, t-1$ & $0.234664^{* * *}$ & 0.098921 & $0.340030^{* * *}$ & $0.128788^{*}$ \\
& $(3.333032)$ & $(1.370826)$ & $(4.498372)$ & $(1.784164)$ \\
\hline$c e \ln i, t-1$ & -0.001408 & -0.177509 & 0.156025 & $-0.408438^{* *}$ \\
\hline Ad-R ${ }^{2}$ & $(-0.413879)$ & $(-1.289086)$ & $(1.233496)$ & $(-2.042333)$ \\
\hline F-value & & & $0.306789^{* * *}$ & -0.269563 \\
\hline Prob(F-statistic) & & & $(3.703813)$ & $(-1.237027)$ \\
\hline T-values are in parentheses. ${ }^{* * *}$ indicates significance level of $1 \%$; ${ }^{* *}$ indicates significance level of 5\%; indicates significance \\
level of $10 \%$.
\end{tabular}

\subsection{Conclusions}

This article tests the spillover effect from technical progress in one sector on the other by constructing two-sector model and using panel data of Chinese equipment manufacturing sector and non-equipment manufacturing sector from 2000 to 2007. The conclusions are as follows: First, expanding Feder's two-sector model, technological progress in equipment manufacturing sector is added to the production function of non-equipment manufacturing sector to study the spillover effect of technical progress in equipment manufacturing sector. Technical progress $T$ has an impact on the whole industry by its elasticity relation $\left(\frac{N}{Y} * \frac{d T_{E}}{T_{E}}\right)$ with $N$, the output of non-equipment manufacturing sector. Meanwhile, the direct contribution from equipment manufacturing sector to industrial economy is tested by analyzing the share of output value of equipment manufacturing sector divided by output in the whole industry and multiplies the growth rate of equipment manufacturing $\operatorname{sector}\left(\frac{E}{Y} * \frac{d E}{E}\right)$, indicating the difference of production capacity between equipment manufacturing sector and non-equipment manufacturing sector. Second, the empirical tests show that the spillover elasticity is between $15.1 \%$ and $15.8 \%$, indicating that technical progress in equipment manufacturing sector has an apparently positive impact on non-equipment manufacturing sector. The notable driving force of equipment manufacturing sector is about $52 \%$ and its marginal productivity is far more than that of non-equipment manufacturing sector. $17 \%, 10 \%$ and $5 \%$ are separately used as the depreciation rate to test the spillover elasticity and similar conclusions are reached, testifying the robustness of the results. Third, in the test of output elasticity of equipment manufacturing sector, under the assumptions of constant returns to scale and variable returns to scale, the output elasticity of capital input is 0.596 and 0.897 , higher than 0.404 and 0.408 , which are the contributions of labor input. It shows that Chinese equipment manufacturing sector belongs to typical capital-intensive industries and capital input has an important effect on output growth. The growth rate of capital and labor both influence the industrial output apparently, and the contribution of investment is above $60 \%$ and labor, $30 \%$. It indicates that Chinese industrial economy is a mode of investment-lead development. Four, in different divisions, the results show that production efficiency of equipment manufacturing sector and equipment updating speed of non-equipment manufacturing sector both affect the technical spillover effect. The higher the production efficiency of equipment manufacturing sector and the equipment updating speed of non-equipment manufacturing sector, more apparent the spillover effect of technical progress. As for the policy, it indicates that investments in research and development of equipment manufacturing sector are needed and innovation abilities, production efficiencies and the equipment updating speed of other industrial sectors should be promoted, to develop the driving force of equipment manufacturing sector to the whole industrial economy.

\section{References}

Aghion P., Howitt P., 1992. A model of growth through creative destruction. Econometrica, 60(2): 323-351. http://dx.doi.org/10.2307/2951599

Barro R. J., Sala-i-Martin X., 1997. Technological diffusion, convergence, and growth. Journal of Economic Growth, 2(1): 1-26. http://dx.doi.org/10.1023/A:1009746629269

Borensztein E., Gregorio J. D., Lee J. W., 1998. How Does Foreign Direct Investment Affect Economic Growth. Journal of International Economic, 45(1): 115-135. http://dx.doi.org/10.1016/S0022-1996(97)00033-0

Feder G., 1983. On export and economic growh. Journal of development economics, 12(1): 59-73. ttp://dx.doi.org/10.1016/0304-3878(83)90031-7

Findlay R., 1978. Relative Backwardness, Direct Foreign Investment and the Transfer of Technology: A Simple 
Dynamic Model. Quartely of Journal of Economics, 92(1): 1-16. http://dx.doi.org/10.2307/1885996

Gong Liutang, Xie Danyang, 2004. Factor Mobility and Dispersion in Marginal Products: A Case on China. Economic Research Journal, 39(1): 45-53.

[1] Huang Yongfeng, Ren Ruoen, Liu Xiaosheng, 2002. Capital Stock Estimates in Chinese Manufacturing by Perpetual Inventory Approach. China Economic Quarterly, 1(1): 377-396.

Koizumi T., Kopecky K.J., 1980. Foreign Direct Investment, Technology Transfer and Domestic Employment Effects. Journal of International Economics, 10(1): 1-20. http://dx.doi.org/10.1016/0022-1996(80)90028-8

Markusen R., Venables A.J., 1999. Foreign Direct Investment as a Catalyst for Industrial Development. European Economic Review, 43(2): 335-356. http://dx.doi.org/10.1016/S0014-2921(98)00048-8

Odedokun M. O., 1996. Alternative econometric approaches for analyzing the role of the financial sector in economic growth: time-series evidence from LDCs. Journal of Development Economics, 50(1): 119-146. http://dx.doi.org/10.1016/0304-3878(96)00006-5

Perkins D.H., 1998. Reforming China's Economic System. Journal of Economic Literature, 31(2): 601-645.

Ram R., 1985. Exports and Economic Growth: Some Additional Evidence. Economic Development and Cultural Change, 33(2): 415-425. http://dx.doi.org/10.1086/451468

Ram R., 1987. Exports and Economics Growth in Developing Countries: Evidence from Time-series and Crosssection data. Economics Development and Cultural Change, 36(1): 51-72. http://dx.doi.org/10.1086/451636

Robert W., Alexander J., 1994. The Government Sector, the Export Sector and Growth. De Economist, 142(2): 211220. http://dx.doi.org/10.1007/BF01388166

Rodriguez-Clare A., 1996. Multinationals, Linkages, and Economic Development. American Economic Review, 86(4): 852-873.

Romer P.M., 1990. Endogenous Technology Change. Journal of Political Economy, 98(5): 71-102. http://dx.doi.org/10.1086/261725

Wang Dewen, Wang Meiyan, Chen Lan, 2004. China's Industrial Restructuring, Efficiency and Its Labor Allocation. Economic Research Journal, 39(4): 41-49.

Wang E. C., 2000. A dynamic two-sector model for analyzing the interrelation between financial development and industrial growth. International Review of Economics and Finance, 9(3): 223-241. http://dx.doi.org/10.1016/S1059-0560(99)00052-0

Wang E. C., 1999. Externalities between financial and real sectors in the development process. International Advances in Economic Research, 5(1):149-150. http://dx.doi.org/10.1007/BF02295046 